\title{
An extremely rare case of neuromuscular and vascular hamartoma of the appendix
}

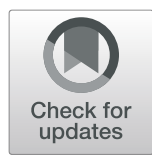

\author{
Takahiro Sasaki ${ }^{1 *}$ (D), Tomohisa Furuhata ${ }^{1}$, Masashige Nishimura' ${ }^{1}$ Tatsunori Ono ${ }^{1}$, Akiyoshi Noda ${ }^{1}$, Hirotaka Koizumi ${ }^{2}$, \\ Nobuyoshi Miyajima ${ }^{1}$ and Takehito Otsubo ${ }^{3}$
}

\begin{abstract}
Background: Neuromuscular and vascular hamartoma is a rare lesion of the small intestine, with only 26 cases reported since its initial description in 1982. No occurrence of hamartoma in the appendix has been reported until now.

Case presentation: A 60-year-old man had been suffering from longstanding right lower quadrant pain. Abdominal computed tomography showed a slight swelling of the appendix as the possible cause of his pain. Laparoscopic appendectomy with partial resection of the cecum was performed for diagnostic and therapeutic purposes. An $18 \times 10-\mathrm{mm}$ lesion located on the tip of the appendix was found in the resected specimen. Pathological examination showed that the lesion was covered with normal mucosa and consisted of adipose tissue, smooth muscle fibers, small vessels, and neural fibers. These findings were consistent with neuromuscular and vascular hamartoma of the appendix.
\end{abstract}

Conclusion: This is the first report of neuromuscular and vascular hamartoma arising from the appendix.

Keywords: Appendix, Neuromuscular and vascular hamartoma

\section{Background}

Neuromuscular and vascular hamartoma $(\mathrm{NMVH})$ is a rare lesion of the small intestine, often clinically presenting as non-specific abdominal pain, recurrence of obstructive symptoms, and gastrointestinal bleeding. First described by Fernando and McGovern in 1982, this lesion consists of an aberrant proliferation of neural, muscular, and vascular elements in the small intestine [1]. Only 26 cases have been reported since its initial description, and NMVH occurred in the small intestine in all cases except one, in which it was found in the cecum [1-20]. To our knowledge, NMVH occurring in the appendix has not been reported in the English literature until now. We report the first case of NMVH of the appendix.

\footnotetext{
* Correspondence: sasa09302005@marianna-u.co.jp

${ }^{1}$ Digestive Disease Center, Toyoko Hospital, St. Marianna University School of Medicine, 3-435, Kosugicho, Nakahara-ku, Kawasaki, Japan

Full list of author information is available at the end of the article
}

\section{Case presentation}

A 60-year-old man complaining of longstanding right lower quadrant pain for 4 years was referred to our hospital for further investigation and intervention. Abdominal examination revealed spontaneous pain in the lower right abdomen without rebound tenderness or palpation of a tumor. Blood examination showed no abnormal values including tumor markers. Abdominal computed tomography (CT) identified a slight swelling of the appendix (about $10 \mathrm{~mm}$ ) without obvious neoplastic tumors or lymphadenopathy (Fig. 1). Colonoscopy showed elevation of the mucosa around the appendiceal orifice (Fig. 2). We considered the swollen appendix to be the cause of his pain and performed a laparoscopic appendectomy with partial resection of the cecum for diagnostic and therapeutic purposes. Intraoperative findings were a slight swelling of the appendix but no tumor exposure on the serosal surface of the appendix and cecum (Fig. 3). The surgical specimen contained a submucosal lesion located on the tip of the appendix that 

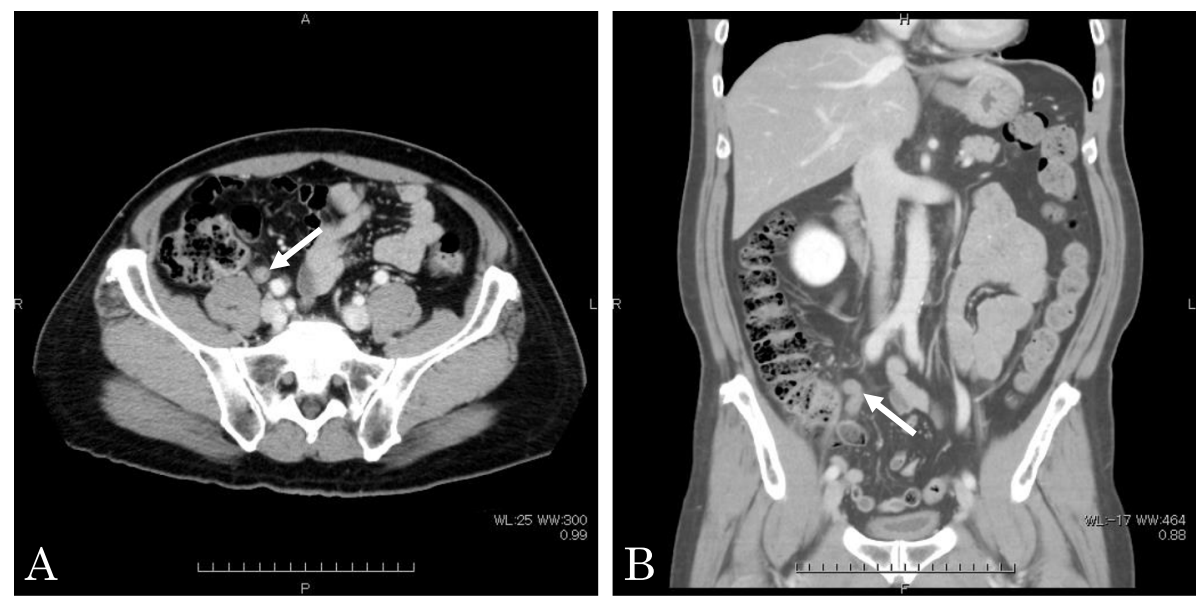

Fig. 1 Abdominal computed tomography (a: axial, b: sagittal). Appendix is slightly swollen (arrow) without obvious neoplastic tumors or lymphadenopathy

measured $18 \times 10 \mathrm{~mm}$ (Fig. 4). Microscopically, this lesion was covered with normal mucosa, arose from submucosa, and contained abundant adipose tissue (Fig. 5). Smooth muscle fiber bundles, small vessels, and neural fiber bundles were collected and scattered irregularly in the submucosa, and there was no evidence of malignancy (Fig. 6). Each component of this lesion was confirmed by immunohistochemical examination. Vascular endothelium, neural fibers, and smooth muscle fibers were immunostained with CD34 (Fig. 7a), S-100 (Fig. 7b), and desmin (Fig. 7c)/smooth muscle actin (Fig. 7d) antibodies, respectively. These pathological findings were consistent with previous reports, and this lesion was

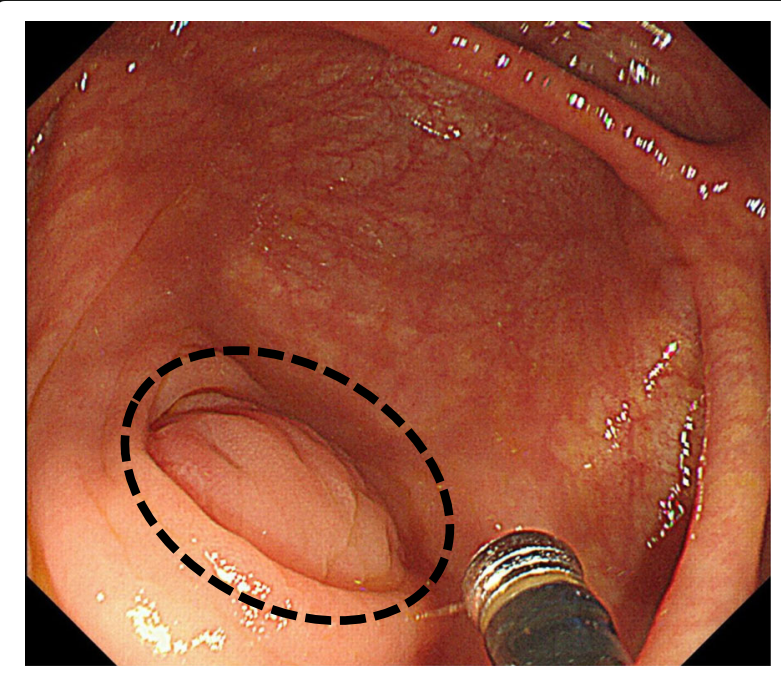

Fig. 2 Colonoscopy. An elevated mucosal lesion is observed around the appendiceal orifice (circle) diagnosed as NMVH. The patient's right lower abdominal pain disappeared immediately after surgery, and was thought to be caused by the NMVH.

\section{Discussion}

To date, 27 cases of NMVH have been reported, including the present case (Table 1). The mean patient age is 53.7 (12-91) years, and there are 10 males and 15 females, with age unknown in 4 cases and sex unknown in 2 cases. Most of the patients complained of abdominal pain, and 3 patients had Crohn's disease as a comorbidity. $\mathrm{NMVH}$ originated in the small intestine in all cases

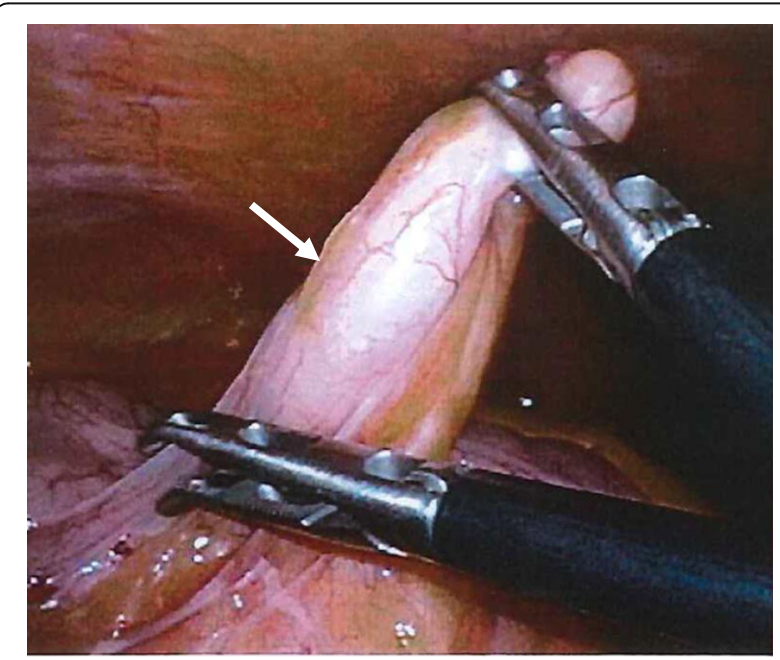

Fig. 3 Laparoscopic appendectomy. Intraoperative findings were a slight swelling of the appendix (arrow), but no other findings on the serosal surface of the appendix and cecum on exposure of the tumor 


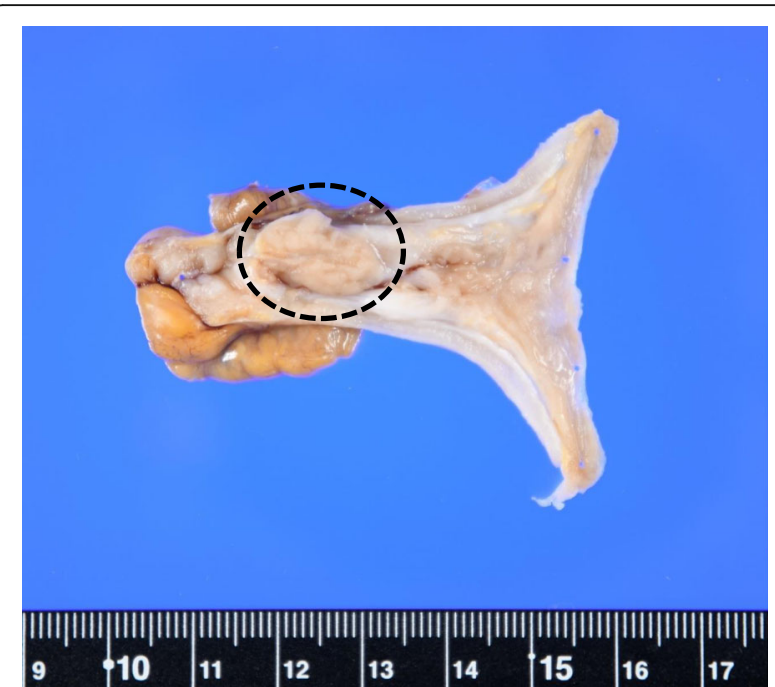

Fig. 4 Surgical specimen. A submucosal lesion measuring $18 \times 10$ $\mathrm{mm}$ (circle) is present on the tip of the appendix
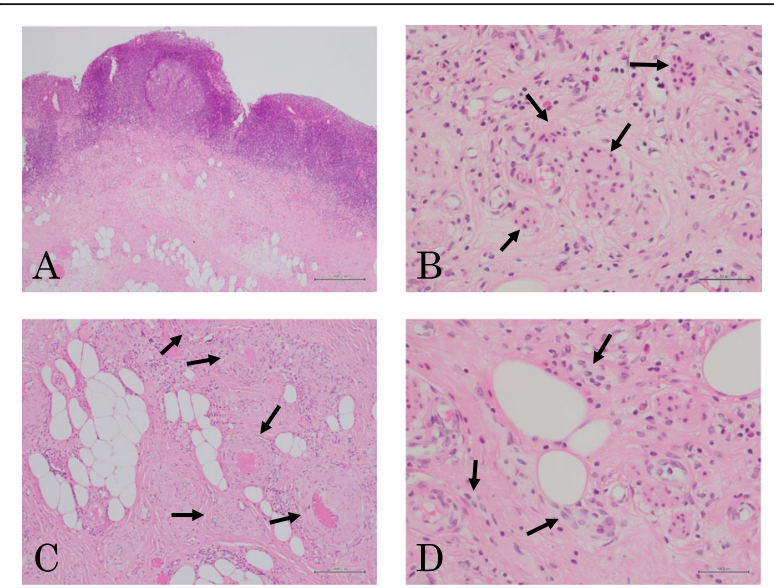

Fig. 6 Hematoxylin and eosin staining. The submucosal lesion was covered with normal mucosa (a) and consisted of adipose tissue (a c, d), smooth muscle fibers (b, arrows), small vessels (c, arrows), and neural fibers (d, arrows). Original magnification, $\mathbf{a}: \times 40 ; \mathbf{b}, \mathbf{d}: \times 200$; c: $\times 100$ except one in which it originated in the cecum [1-20]. Therefore, this report appears to be the first case of $\mathrm{NMVH}$ occurring in the appendix.

The only findings in this case were longstanding right lower quadrant pain and a slight swelling of the appendix on CT imaging. As a cause of the swollen appendix without inflammation, the latency of cancer and carcinoid tumors was considered. However, we presumed that the preoperative diagnosis was less likely to be a progressive disease such as cancer because no worsening of abdominal pain or tumor

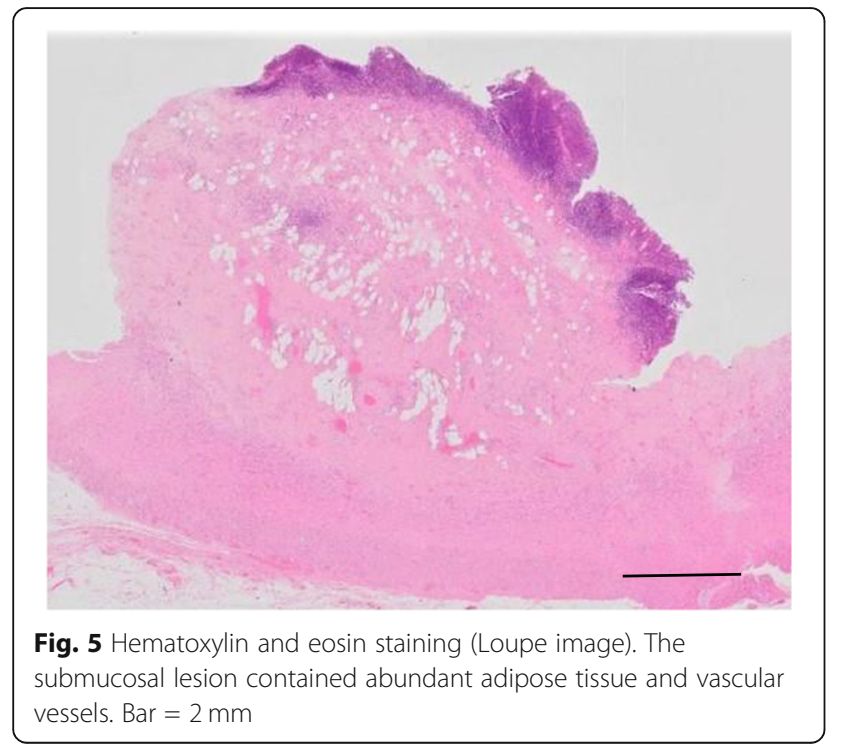

formation had been observed for the 4 years since onset. For these reasons, we performed a laparoscopic appendectomy for diagnostic and therapeutic purposes. The patient's right lower abdominal pain disappeared immediately after surgery, indicating that it was likely caused by the NMVH. Although a detailed mechanism for the abdominal pain was unclear, a rise in the internal pressure of the appendix was considered as one possible cause.

NMVH has been thought to be a hamartoma that consists of an aberrant proliferation of neural, muscular, and vascular elements in the intestine [1]. However, Shepherd and Jass suggested that NMVH may represent an abnormal histologic consequence of chronic inflammatory bowel disease, especially Crohn's disease [3]. Other authors reported that NMVH might not be a rare entity but rather a process of chronic inflammation [22, 23]. However, considering that most of the patients in the previous reports did not exhibit prominent fibrosis of the intestinal wall when observed in the chronic inflammatory state, it is thought that NMVH may exist as a separate entity [18]. For such reasons, the debate continues as to whether this lesion is truly a hamartoma or represents a "burnt-out" phase of various chronic pathologies.

The case presented here showed no histological features such prominent fibrosis that would indicate active or "burnt out" Crohn's disease or another reactive process induced by chronic inflammation. Therefore, we consider this NMVH of the appendix to be an entity separate from any special state of chronic inflammation. 

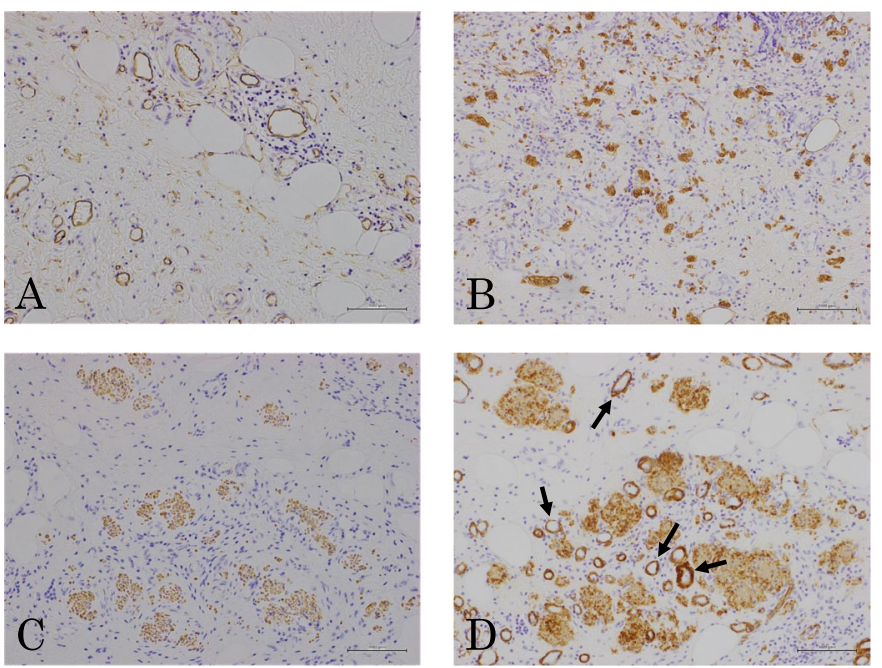

Fig. 7 Immunohistochemical staining. Immunohistochemical staining revealed vascular endothelium (a: CD34), neural fibers (b: S-100), and smooth muscle fibers including perivascular fibers (arrows) (c: Desmin, d: smooth muscle actin), respectively. Immunoperoxidase staining. Original magnification, $\mathbf{a}: \times 200 ; \mathbf{b}, \mathbf{c}, \mathbf{d}: \times 100$

Table 1 Summary of 27 cases of neuromuscular and vascular hamartoma

\begin{tabular}{|c|c|c|c|c|c|c|c|}
\hline & Author & Year & Age & sex & Symptom & Origin & Comorbidity \\
\hline 1 & Fernando [1] & 1982 & 30 & Female & Anemia & Small intestine & \\
\hline 2 & Fernando [1] & & 36 & Female & Abdominal pain, vomiting & Small intestine & \\
\hline 3 & Smith [2] & 1986 & 51 & Female & Abdominal pain, vomiting & Small intestine & \\
\hline 4 & Shepherd [3] & 1987 & 34 & Female & Abdominal pain, vomiting & Small intestine & Crohn's disease \\
\hline 5 & Shepherd [3] & & 58 & Male & Abdominal pain, diarrhea & Small intestine & Crohn's disease \\
\hline 6 & Shepherd [3] & & 73 & Female & Abdominal pain & Small intestine & \\
\hline 7 & Shepherd [3] & & 63 & Female & Abdominal pain & Small intestine & \\
\hline 8 & Kwasnik [4] & 1989 & 91 & Male & ND & Small intestine & \\
\hline 9 & Salas [5] & 1990 & ND & ND & ND & Small intestine & \\
\hline 10 & Cortina [6] & 1999 & 73 & Male & Bowel obstruction & Small intestine & \\
\hline 11 & Cortina [6] & & 76 & Male & Bowel obstruction & Small intestine & \\
\hline 12 & De Sanctis [7] & 2001 & 76 & Female & Anemia & Small intestine & \\
\hline 13 & Scintu [8] & 2001 & 50 & Male & Bowel obstruction & Small intestine & \\
\hline 14 & Shiomi [9] & 2002 & 76 & Female & Asymptomatic & Cecum & \\
\hline 15 & Company [10] & 2005 & 76 & Female & ND & Small intestine & \\
\hline 16 & Theodosiou [11] & 2009 & 60 & Male & Abdominal pain & Small intestine & \\
\hline 17 & Krishnamurthy [12] & 2010 & 32 & Male & Abdominal pain & Small intestine & \\
\hline 18 & Kaplan [13] & 2013 & 12 & Female & Abdominal pain, vomiting & Small intestine & \\
\hline 19 & Ren [14] & 2014 & ND & Female & Abdominal pain, anemia & Small intestine & \\
\hline 20 & Ren [14] & & ND & ND & ND & Small intestine & \\
\hline 21 & Setaffy [15] & 2015 & ND & ND & ND & Small intestine & \\
\hline 22 & Crothers [16] & 2014 & 73 & Female & ND & Small intestine & \\
\hline 23 & Liu [17] & 2015 & 27 & Female & Abdominal pain, diarrhea & Small intestine & \\
\hline 24 & Elster [18] & 2016 & 59 & Female & Abdominal pain, vomiting & Small intestine & Crohn's disease \\
\hline 25 & Caruso [19] & 2018 & 58 & Male & Abdominal pain, anemia & Small intestine & \\
\hline 26 & Pattnaik [20] & 2019 & 45 & Male & ND & Small intestine & \\
\hline 27 & Our case & 2020 & 60 & Male & Abdominal pain & Appendix & \\
\hline
\end{tabular}




\section{Conclusion}

We experienced a case of $\mathrm{NMVH}$ occurring in the appendix. Although NMVH is a benign disease, it should be included in the differential diagnosis of neoplastic lesions not only in the small intestine but also in the appendix.

\section{Abbreviations}

$\mathrm{CT}$ : Computed tomography; NMVH: Neuromuscular and vascular hamartoma

\section{Acknowledgements}

Authors thank Prof. Tina Tajima of St. Marianna University School of Medicine for her meticulous English editing of the paper.

\section{Authors' contributions}

Takahiro Sasaki described and designed the report. Tomohisa Furuhata edited the manuscript. Takehito Otsubo supervised the overall writing of the manuscript. Masashige Nishimura, Tatsunori Ono, Akiyoshi Noda, Hirotaka Koizumi, and Nobuyoshi Miyajima collected the data and discussed the contents of the manuscript. All authors read and approved the final manuscript.

\section{Funding}

This study was not funded.

\section{Availability of data and materials}

All data generated or analyzed during this study are included in this published article.

\section{Ethics approval and consent to participate}

Written informed consent was obtained from the patient for publication of this case report and any accompanying images.

\section{Consent for publication}

Written informed consent was obtained from the patient for publication of this case report and any accompanying images.

\section{Competing interests}

The authors declare no potential conflicts of interest.

\section{Author details}

${ }^{1}$ Digestive Disease Center, Toyoko Hospital, St. Marianna University School of Medicine, 3-435, Kosugicho, Nakahara-ku, Kawasaki, Japan. ²Department of Pathology, Toyoko Hospital, St. Marianna University School of Medicine, 3-435, Kosugicho, Nakahara-ku, Kawasaki, Japan. ${ }^{3}$ Department of Gastroenterological and General Surgery, St. Marianna University School of Medicine, 2-16-1, Sugao, Miyamae-ku, Kasawaki, Japan.

Received: 22 June 2020 Accepted: 4 August 2020

Published online: 24 August 2020

\section{References}

1. Fernando SS, McGovern VJ. Neuromuscular and vascular hamartoma of small bowel. Gut. 1982;23:1008-12.

2. Smith CE, Filipe MI, Owen WJ. Neuromuscular and vascular hamartoma of small bowel presenting as inflammatory bowel disease. Gut. 1986;27:964-9.

3. Shepherd NA, Jass JR. Neuromuscular and vascular hamartoma of the small intestine: is it Crohn's disease? Gut. 1987;28:1663-8.

4. Kwasnik EM, Tahan SR, Lowell JA, Weinstein B. Neuromuscular and vascular hamartoma of the small bowel. Dig Dis Sci. 1989;34:108-10.

5. Salas A, Casellas F, Sanz J, Garcia F, Margarit C, Malagelada JR. Neuromesenchymal hamartoma of the small bowel. J Clin Gastroenterol. 1990;12:705-9.

6. Cortina G, Wren S, Armstrong B, Lewin K, Fajardo L. Clinical and pathologic overlap in nonsteroidal anti-inflammatory drug-related small bowel diaphragm disease and the neuromuscular and vascular hamartoma of the small bowel. Am J Surg Pathol. 1999;23:1414-7.

7. de Sanctis S, Qureshi T, Stebbing JF. Clinical and pathologic overlap in nonsteroidal anti-inflammatory drug-related small bowel diaphragm disease and the neuromuscular and vascular hamartoma of the small bowel. Am J Surg Pathol. 2001;25:539-41.

8. Scintu F, Capra F, Giordano M, Frau G, Mascia R, Comella D, et al. [Neuromuscular and vascular hamartoma of the small intestine. Report of a clinical case and review of the literature]. In Italian. Chir Ital. 2001;53:393-8.

9. Shiomi T, Kameyama K, Kawano Y, Shimizu Y, Takabayashi T, Okada Y. Neuromuscular and vascular hamartoma of the cecum. Virchows Arch. 2002; 440:338-40.

10. Company MM, Usamentiaga E, Torralba J, Bonet L. [Small bowel diaphragm disease associated with NSAIDs with histology of neuromuscular and vascular hamartoma. Case report and literature review]. In Spanish. Gastroenterol Hepatol. 2005;28:228-31.

11. Theodosiou E, Voulalas $G$, Salveridis N, Pouggouras K, Manafis K, Christodoulidis K. Neuromesenchymal hamartoma of small bowel--an extremely rare entity: a case report. World J Surg Oncol. 2009;7:92.

12. Krishnamurthy $V$, Basavaraj $\vee$, Sunila, Vimalambike MG. Neuromuscular and vascular hamartoma of the small bowel: a rare cause of intestinal obstruction. J Lab Phys. 2010;2:109-10.

13. Kaplan JL, Goldstein AM, Shenoy-Bhangle A, Badizadegan K. Neuromuscular and vascular hamartoma of the small intestine in a child. J Pediatr Gastroenterol Nutr. 2013;56:e33-5.

14. Ren B, Cao W. Neuromuscular and vascular hamartoma: is it a true hamartoma? J Clin Pathol. 2014;67:284-7.

15. Setaffy L, Osuna MJ, Plieschnegger W, del Pino Florez Rial M, Geboes K, Langner C. Cryptogenic multifocal ulcerous stenosing enteritis (CMUSE), and neuromuscular and vascular hamartoma (NMVH): two sides of the same coin? Endoscopy. 2015;47:345-8.

16. Crothers JW, Zenali M. Neuromuscular and vascular hamartoma of the small intestine: an exuberant reparative process secondary to chronic inflammation. Int J Surg Pathol. 2015;23:673-6.

17. Liu N, Pan Y, Li ZS, Shi YP, Zhang XY, Wu GS, et al. Neuromuscular and vascular hamartoma: a rate entity or special phase of Crohn's disease. J Dig Dis. 2015;16:52-4

18. Elstner KE, Vickers CR, Gett RM, Qiu MR, Killen LV. Neuromuscular and vascular hamartoma as an unusual cause of small bowel obstruction. Int J Surg Case Rep. 2016;26:1-3.

19. Caruso ML, Cavalcanti E, De Michele F, Ignazzi A, Carullo R, Mastronardi M. Small bowel capsule endoscopy revealing neuromuscular and vascular hamartoma of the jejunum: a case report. Medicine (Baltimore). 2018;97: e0196.

20. Pattnaik SA, Mitra S, Mishra TS, Purkait S, Kumar P, Naik S. A vasculitisassociated neuromuscular and vascular hamartoma presenting as a fata form of abdominal cocoon. Int J Surg Pathol. 2019;27:108-15.

\section{Publisher's Note}

Springer Nature remains neutral with regard to jurisdictional claims in published maps and institutional affiliations.

\section{Submit your manuscript to a SpringerOpen ${ }^{\circ}$ journal and benefit from:}

- Convenient online submission

- Rigorous peer review

- Open access: articles freely available online

- High visibility within the field

- Retaining the copyright to your article

Submit your next manuscript at $>$ springeropen.com 